\title{
HEPÁTICAS TALOSAS DO PARQUE NACIONAL DA TIJUCA, RIO DE JANEIRO, BRASIL.
}

\author{
Denise P. da Costa (1) \\ Olga Yano (2)
}

\begin{abstract}
RESUMO - Onze espécies de hepáticas talosas são mencionadas para o Parque Nacional da Tijuca, Rio de Janeiro, Brasil: Dumortiera hirsuta (Sw.) Nees, Marchantia papillata Raddi, Metzgeria aurantiaca Steph., M. dichotoma (Sw.) Nees, M. furcata (L.) Dum., Monoclea forsteri Hook., Riccardia cataractarum (Spruce) Hell, $R$. chamedryfolia (With.) Grolle, Symphyogyna aspera Steph. ex Evans, $S$. brasiliensis Nees \& Mont. e $S$. podophylla (Thumb.) Mont. \& Nees. Metzgeria aurantiaca e Riccardia cataractarum estāo sendo mencionadas pela primeira vez para o Rio de Janeiro. Descrição, e distribuição geográfica brasileira para cada espécie são apresentadas.
\end{abstract}

\begin{abstract}
Eleven species of thallose liverworts are mentioned for the Tijuca National Park, Rio de Janeiro, Brazil: Dumortiera hirsuta (Sw.) Nees, Marchantia papillata Raddi, Metzgeria aurantiaca Steph., $M$. dichotoma (Sw.) Nees, $M$. furcata (L.) Dum., Monoclea forsteri Hook., Riccardia cataractarum (Spruce) Hell, $R$. chamedryfolia (With.) Grolle, Symphyogyna aspera Steph. ex Evans, S. brasiliensis Nees \& Mont., and S. podophylla (Thumb.) Mont. \& Nees. Metzgeria aurantia$c a$ and Riccardia cataractarum are mentioned for the first time for Rio de Janeiro State. Description, and Brazilian geographical distribution for each taxon are presented.

Key-words: thallose liverworts, Tijuca National Park.
\end{abstract}

\section{Introdução}

O estudo das briófitas do Parque Nacional da Tijuca, no Estado do Rio de Janeiro, foi iniciado em 1983 com a famnia Leucobryaceae, extendendo-se atualmente para as hepáticas talosas.

O parque situa-se no domínio Tropical Atlântico na Serra do Mar, na região sudeste do Estado do Rio de Janeiro, com uma área aproximada de 3300 hectares. Foi criado em 6 de julho de 1961 pelo Decreto Federal n 50923 com o nome de Parque Nacional do Rio de Janeiro e, pelo Decreto Federal no 183 de 8 de fevereiro de 1962, passou a se chamar Parque Nacional da Tijuca, onde teve seus limites demarcados (Centro de Conservaçăo da Natureza, 1966).

A vegetação da região é constituída de formações secundárias, pois a ocupação humana destruiu as matas para extração de madeiras e atividades agrícolas, principalmente cultura de cana-de-açúcar e café. Assim, sua vegetaçăo original foi destruída por sucessivos cultivos provocando a redução da vazão dos cursos d’água que abasteciam a população. Para a recuperação da cobertura vegetal começaram então as desapropriaçōes das áreas montanhosas. Este trabalho durou 13 anos, durante os quais foram plantadas cem mil árvores de diferentes espécies. Atualmente, a vegetaçāo do parque é uma combinação do reflorestamento com a regeneração da vegetação natural. Algumas áreas da vegetação primitiva ficaram preservadas e disseminaram suas espécies enriquecendo as comunidades biológicas do local.

1. Bolsista do (CNPq).

2. Instituto de Botânica, Caixa Postal 4005, 01051 - São Paulo, SP, Brasil. 
O parque é formado por três áreas distintas e fisicamente separadas: primeira, a Pedra Bonita e a Pedra da Gávea a sudoeste; segunda, central alongada para o leste (Corcovado, Sumaré, Formiga, Mirantes Dona Marta, Queimado, Vista Chinesa e Mesa do Imperador) e terceira a noroeste, que é a floresta da Tijuca. O ponto culminante é o Pico da Tijuca com 1021m de altitude. A elevada precipitação pluvial (+ de $2000 \mathrm{~mm}$ anuais) favorece o desenvolvimento de uma vegetação florestal exuberante (Pádua \& Coimbra Filho, 1979).

As briófitas do Parque Nacional da Tijuca não estão mencionadas em trabalhos antigos ou recentes, apesar do local ser atualmente pouco perturbado, de fácil acesso e apresentar condições ambientais favoráveis para o crescimento de briófitas.

O objetivo do trabalho é contribuir para a flora briofítica do Rio de janeiro, e conseqüentemente, do Brasil.

\section{Material e Métodos}

A metodologia de coleta, herborização e preservação foi baseada em Yano (1984a).

As excursões de coleta de material briofítico foram realizadas desde agosto de 1983 até novembro de 1985, mensalmente.

No laboratório, o material foi examinado ao microscópio estereoscópico binocular. Os cortes foram feitos à mão livre, com gilete, ao estereomicroscópio, em seguida montados entre lâmina e lamínula com água e observados ao microscópio óptico para estudo das estruturas anatômicas.

Para identificação das espécies coletadas, foram consultadas as chaves de identificação de Hässel de Menéndez (1962), de Hell (1969), de Griffin III (1979) e de Schuster (1984).

O material examinado e identificado foi colocado em saquinhos de papel, etiquetados, registrados e incluídos no Herbário do Jardim Botânico do Rio de Janeiro (RB).

Os locais de coleta visitados no parque estão discriminados na Figura 1, a saber: 1) Pedra da Gávea; 2) Pedra Bonita; 3) Floresta da Tijuca; 4) Pico da Tijuca; 5) Açude da Solidão; e 6) Paineiras.

\section{Espécies Estudadas}

Dumortiera hirsuta (Sw.) Nees, Nova Acta Acad. Cesar, Leop. Carol. 12: 410. 1824. Basiônimo: Marchantia hirsuta Sw., Prodr. FI. Ind. Occ. 145. 1788.

Localidade-tipo: Jamaica

Gametófitos monóicos, verde-escuros, ramificação dicotômica, 25-55mm de comprimento, 5-11 mm de largura. Margem plana, nervura pouco pronunciada, asa pluriestratificada, rizóides de dois tipos: lisos e tuberculados, inseridos na superfície ventral do talo. Em corte transversal do talo: epiderme superior clorofilada, parênquima com 25 camadas de células de espessura na região da vita, 7 camadas de células na asa. Câmaras fotossintéticas reduzidas ou ausentes. Receptáculos masculinos e femininos não examinados.

Distribuição geográfica: Amazonas, Mato Grosso, Minas Gerais, Rio de Janeiro, São Paulo, Paraná e Rio Grande do Sul (Yano, 1984b).

Material examinado: Rio de Janeiro: município de Rio de Janeiro, Parque Nacional da Tijuca, Pedra da Gávea, col. D.P. Costa 7, 14-VIII-1983 (RB230186); idem, Paineiras, col. Schwacke s/n, 1876 (RB220383); idem, col. Ule s/n, 1876 (RB220384).

Comentários - D. hirsuta cresce sobre pedras ou solo úmido, formando placas. Os gametófitos estéreis são distintos das demais Marchantiales, exceto do gênero Monoclea Hook., porque não possuem tecido fotossintético e nem poros. Dumortiera difere de Monoclea porque não tem cerdas nas margens, não possui vitas e apresenta pequenas escamas ventrais que orientam os rizóides contra a superfície ventral do gametófito. 


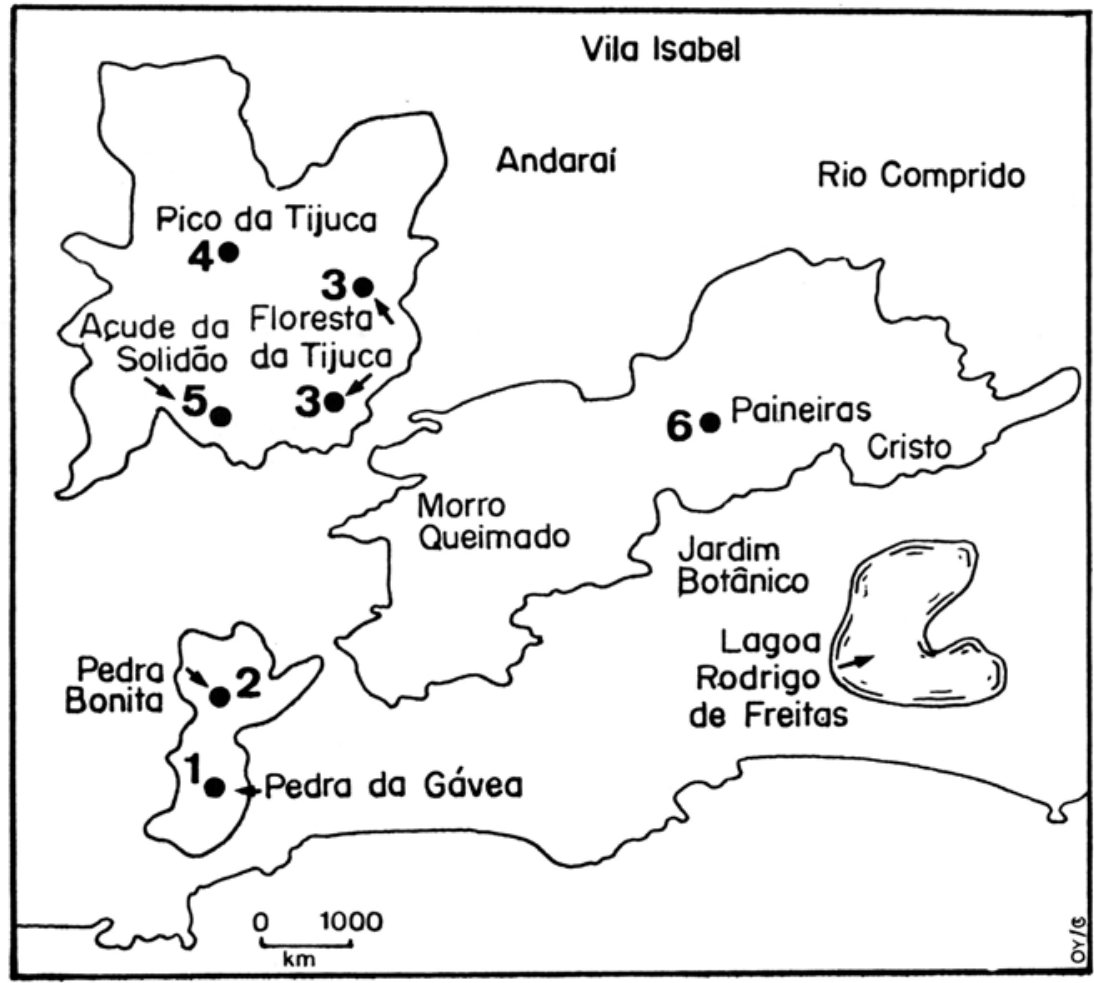

Figura 1. Locais de coleta, Parque Nacional da Tijuca, RJ.

Marchantia papillata Raddi, Mem. Soc. Ital. Modena 19: 44. 1823. (Figuras 2-8). Localidade-tipo: Rio de Janeiro.

Gametófitos coriáceos, verde-escuros, superfície ventral purpúrea, 10-30 × 5-10mm. Ramificações bifurcadas, margem hialina, ondulada, costa pronunciada, rizóides de dois tipos: lisos e tuberculados, inserindo-se sobre a costa. Em corte transversal, células epidérmicas em uma só camada, poros formados por anéis concêntricos (6-8) câmaras aeríferas, tecido parenquimático formado por até 25 camadas na asa. Células parenquimáticas com pontuações. Escamas ventrais avermelhadas, com apêndices na superfície ventral. Receptáculos masculino e feminino pedunculados, com discos e escamas.

Distribuição geográfica: Mato Grosso, Minas Gerais, Rio de Janeiro, São Paulo e Rio Grande do Sul (Yano, 1984b).

Material examinado: Rio de Janeiro: município de Rio de Janeiro, Parque Nacional da Tijuca, Floresta da Tijuca, col. D.P. Costa 167, 8-V-1985 (RB233569).

Comentários - $M$. papillata cresce sobre paredão úmido ou nas margens de rios encachoeirados. Apresentam vários receptáculos distribuídos sobre o talo do gametófito, variando de 3-5. Gametófito mais estreito que o de $M$. chenopoda $\mathrm{L}$.

Metzgeria aurantiaca Steph., Bull. Herb. Boissier 7: 938.1899. (Figuras 9-11).

Localidade-tipo: Brasil. 
Gametófitos dióicos, prostrados, verde-claros a verde-amarelados, $10-25$ x 0,5-1,0mm. Ramificações dicotômicas sucessivas e de igual desenvolvimento, talo plano, asa com bordos planos. Em corte transversal, asas uniestratificadas, com 14 células de largura, paredes irregulares; costa mediana igual em ambos os lados, com duas fileiras de células tanto do lado ventral como dorsal, células medulares com paredes espessas, até 6 camadas; rizóides curtos e retos, ocorrendo nos bordos e no lado ventral da nervura mediana, cada célula origina apenas um, porém ausentes nas superfícies da asa.

Distribuição geográfica: Minas Gerais e São Paulo (Yano, 1984b).

Material examinado: Rio de Janeiro: município de Rio de Janeiro, Parque Nacional da Tijuca, Rio dos Macacos, col.D.P. Costa 106pp., 13-IX-1984 (RB240739).

Comentários - $M$. aurantiaca cresce sobre barrancos, pedras ou madeira em decomposição ao longo das picadas e no interior da mata, formando pequenos emaranhados. Esta espécie está sendo citada pela primeira vez para o Estado do Rio de Janeiro.

Metzgeria dichotoma (Sw.) Nees, Naturg. Europ. Leberm. 3: 408. 1838. (Figuras 12-15).

Basiônimo: Jungermannia dichotoma Sw., Prodr. FI. Ind. Occ. 145. 1788.

Localidade-tipo: Jamaica.

Gametófitos dióicos, prostrados, verde-claros ou verde-esbranquiçados, 8-20 x 0,41,0mm. Ramificações dicotômicas simétricas, margens planas com rizóides. Em corte transversal, asas uniestratificadas, nervura mediana saliente tanto na superfície ventral como na dorsal, até 4 células na superfície ventral e até 6 células na dorsal; células medulares espessadas e alaránjadas; rizóides 1-2 por célula nas margens e numerosos na nervura.

Distribuição geográfica: Minas Gerais, Rio de Janeiro, São Paulo e Rio Grande do Sul (Yano, 1984b).

Material examinado: Rio de Janeiro: município de Rio de Janeiro, Parque Nacional da Tijuca, Rio dos Macacos, col. D.P. Costa 113, 13-IX-1984 (RB240738).

Comentários - $M$. dichotoma cresce formando placas sobre barrancos, pedras ou madeiras em decomposição, área muito úmida. Apresenta simetria dicotômica, com nervura mediana saliente em ambas as superfícies.

Metzgeria furcata (L.) Dum., Rec. d’Obs. Jung. 1: 26. 1835. (Figuras 16-19).

Basiônimo: Jungermannia furcata L., Spec. PI. 1136. 1753.

Localidade-tipo: Europa.

Gametófitos dióicos, prostrados, fortemente aderidos ao substrato, verde-esbranquiçados a verde-amarelados, 7-15 x 0,5-1,0mm. Ramificações dicotômicas simétricas. Em corte transversal, asas uniestratificadas até 14 células de largura; nervura mediana saliente de ambos os lados, 3-4 fileiras de células do lado ventral e 2 fileiras do lado dorsal; células medulares com paredes pouco espessas, com até 6 camadas; rizóides inteiros ou com pontas ramificadas, prendendo-se fortemente ao substrato; nas asas e bordos cada célula origina apenas um rizóide. As gemas abundantes destacando-se após atingir desenvolvimento completo.

Distribuição geográfica: Bahia, Rio de Janeiro, São Paulo e Rio Grande do Sul (Yano, 1984b).

Material examinado: Rio de Janeiro: município de Rio de Janeiro, Parque Nacional da Tijuca, Rio dos Macacos, col. D.P. costa 106pp., 13-IX-1984 (RB240739).

Comentários - $M$. furcata cresce sobre troncos ou folhas de árvores ou no chão da mata, formando emaranhado, podendo-se misturar com outras briófitas. As inúmeras sinonímias foram citadas em Hell (1969).

Figuras 2-8. Marchantia papillata - 2. Aspecto geral do gametofito; 3. Corte transversal do gametofito; 4. Escamas (vista ventral); 5 . Detalhe da escama; 6. Detalhe do apêndice; 7. Escamas (corte transversal); 8. Poro com filamentos fotossintéticos. 

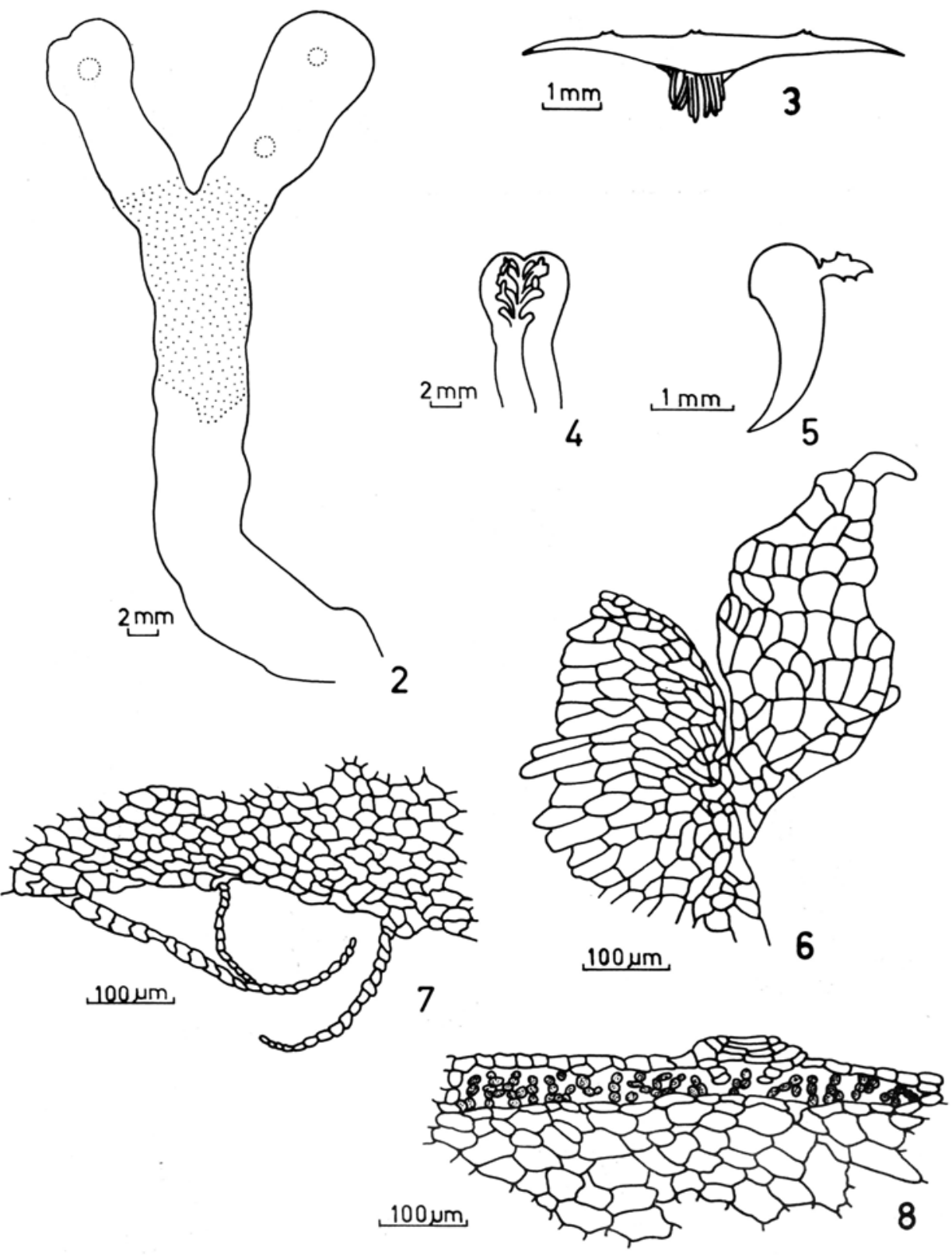

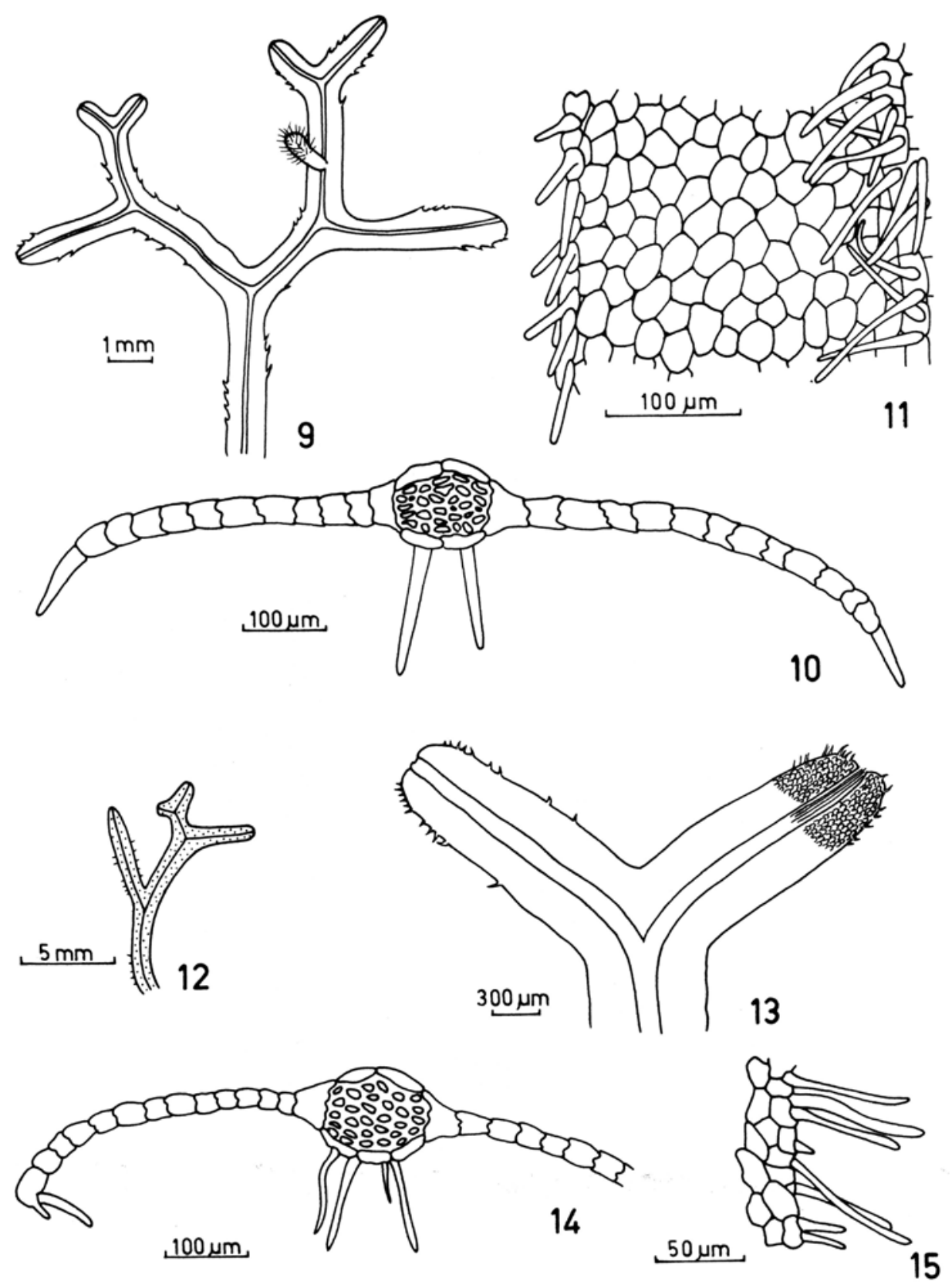
Monoclea forsteri Hook., Musc. Exot. 2: 174. 1820.

Localidade-tipo: Ilhas Austrais.

Gametófitos dióicos, prostrados, verde-olivas, 20-50 x 0,8-1,5mm. Ramificaçōes dicotômicas sucessivas ficando a parte superior do talo larga e sinuosa, sem poros aerfferos, câmaras fotossintéticas e escamas ventrais; rizóides presentes na região mediana da superfície ventral. Em corte transversal o talo é plano dorsalmente e convexo ventralmente, com 5-11 camadas de células na região mediana diminuindo gradualmente em direção à margem. Anterídios e arquegônicos em câmaras no interior do talo.

Distribuição geográfica: Amazonas, Rio de Janeiro e São Paulo (Yano, 1984b).

Material examinado: Rio de Janeiro: município de Rio de Janeiro, Parque Nacional da Tijuca, Rio dos Macacos, col. D.P. Costa 121, 13-IX-1984 (RB240737).

Comentários - $M$. forsteri cresce nos barrancos ou pedras próximos de rios e cachoeiras, formando placas aderidas ao substrato. A nível de gênero, os gametófitos de Monoclea são distintos dos de Dumortiera Nees por apresentarem cerdas nos bordos e cor verdeamarelada; também os rizóides não confluem até a nervura mediana nem estão orientados.

Riccardia cataractarum (Spruce) Hell, Bolm. Fac. Filos. Ciênc. Univ. S.Paulo sêr. Bot. 25: 97.1969.

Basiônimo: Aneura cataractarum Spruce, Bull. Soc. Bot. France 36(suppl.): 195. 1889.

Localidade-tipo: Paraguai.

Gametófitos dióicos, prostrados, verde-escuros ou castanhos nas partes velhas, 20$40 \times 4-8 \mathrm{~mm}$. Ramificaçōes pinadas, pinas irregulares, papilas mucilageníferas próximas ao ápice. Em corte transversal, biconvexo, até 6 camadas de células de espessura, sem asas; rizóides da margem do talo em contato com o substrato.

Distribuição geográfica: São Paulo (Yano, 1984b).

Material examinado: Rio de Janeiro: município de Rio de Janeiro, Parque Nacional da Tijuca, col. D.P. Costa 129, 25-XI-1984 (RB230194).

Comentários - $R$. cataractarum cresce sobre barrancos, pedras ou entre galhos em decomposição, lugares muito úmidos, geralmente em água corrente, ficando muitas submersa, formando pequenas placas que se entrelaçam com outras plantas que crescem no local.

Os oleocorpos são moniliformes ou fusiformes, ocorrendo nas células que contém plastos, um oleocorpo por célula, raramente dois.

A espécie está sendo citada pela primeira vez para o Rio de Janeiro.

Riccardia chamedryfolia (With.) Grolle, Trans. Brit. Bryol. Soc. 5: 772. 1969.

Basiônimo: Jungermannia chamedryfolia With., Bot. Arrang. veg. Natur. Great Brit. 2: 699. 1776.

Localidade-tipo: Ilhas Britânicas ?

Gametófitos monóicos, sinuosos, prostrados, verde-claros, 10-30 x 1,0-2,5mm. Ramificações plano-convexas ou biconvexas, até 7 camadas de células de espessura, sem asas e sem rizóides.

Distribuição geográfica: Amazonas, Minas Gerais e São Paulo (Yano, 1984b).

Material examinado: Rio de Janeiro: município de Rio de Janeiro, Parque Nacional da Tijuca, col. D.P. Costa 8, 10-IX-1983 (RB230141).

Comentários - chamedryfolia cresce em barrancos ou pedras próximas de rios, aderidas ao substrato. Os oleocorpos são fusiformes ou esféricos em quase todas as células, normalmente apenas um por célula, raramente 2-3 (camadas mais profundas).

Figuras 9-11. Metzgeria aurantiaca - 9. Aspecto do gametófito; 10. Corte transversal do gametófito, nervura central e rizóides; 11. Rizóides da margem e nervura (vista ventral). Figuras 12-15. Metzgeria dichotoma - 12. Aspecto do gametofito; 13. Detalhe do gametófito; 14. Corte transversal do gametófito, nervura central e rizóides; 15 . Rizóides da margem. 

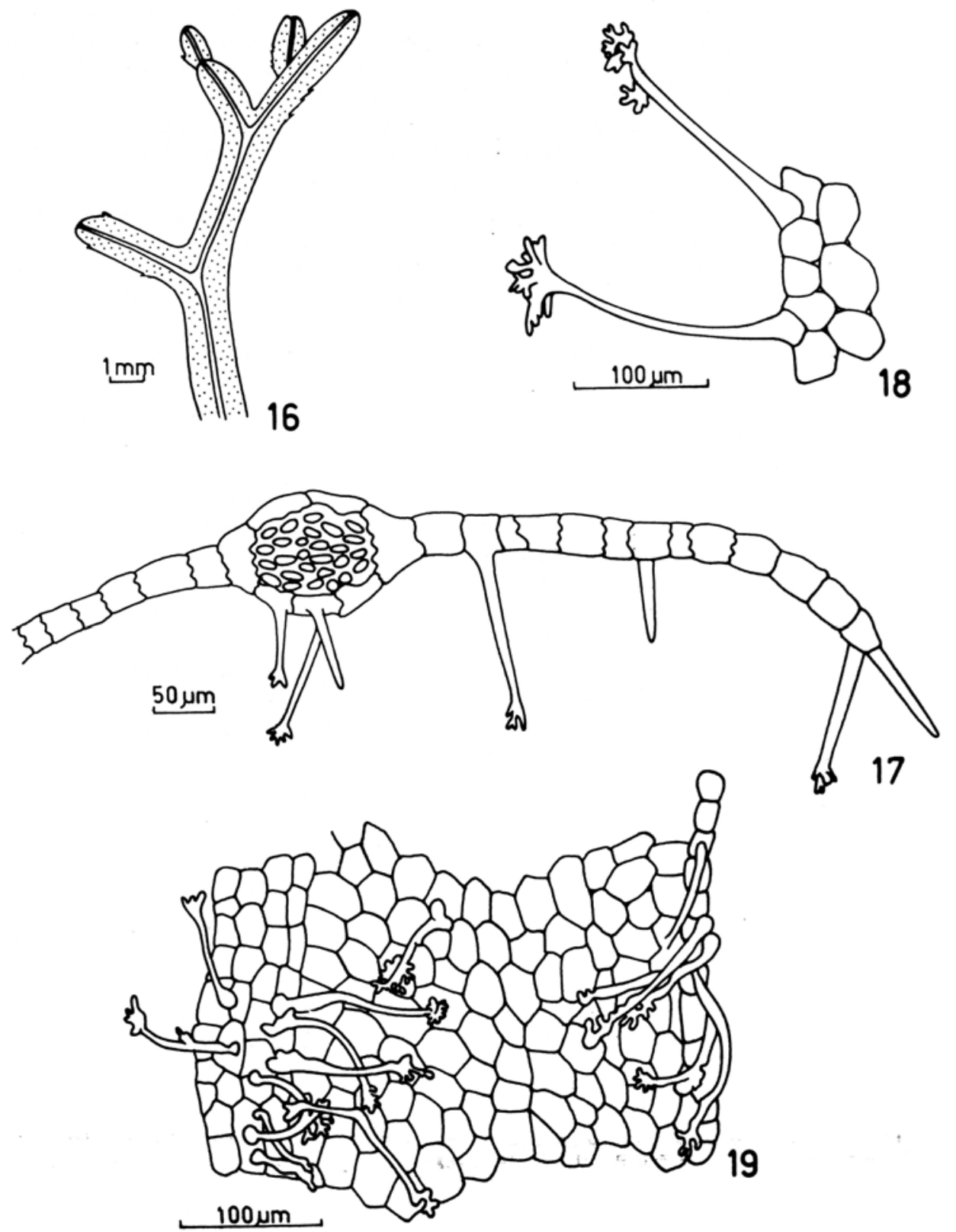
A espécie era conhecida como $R$. sinuata (Hook.) Trevis., até que Grolle (1969) baseado no trabalho de Dillenius de 1741 , a colocasse como sinônimo de $R$. chamedryfolia. .

Riccardia chamedryfolia está sendo mencionada pela primeira vez para o Rio de Janeiro.

Symphyogyna aspera Steph. ex Evans., Trans.Conn. Acad. Arts Sc. 27: 42.1925. Localidade-tipo: México.

Gametófitos dióicos, ondulados ou sinuosos, prostrados e parte ascendente, verdeclaros ou verde-amarelados, $15-90$ x 3-9mm. Ramificaçōes bifurcadas, margens lisas até lobadas, papilas mucilageníferas abundantes no ápice do talo, nervura mediana nítida. Em corte transversal, células da nervura com até quatro feixes prosenquimáticas, asa uniestratificada, rizóides abundantes; nervura mediana podendo também ocorrer nas margens do talo. Anterídios e arquegônios recobertos por uma escama na região dorsal do talo.

Distribuição geográfica: Minas Gerais, Rio de Janeiro, São Paulo, Santa Catarina e Rio Grande Do Sul (Yano, 1984b).

Material examinado: Rio de Janeiro: município de Rio de Janeiro, Parque Nacional da Tijuca, col.D.P.Costa 34, 10-IX-1983 (RB230168).

Comentários - $S$. aspera cresce no solo úmido ou pedras de lugar sombreado ou no interior da mata formando pequenas placas.

A localidade-tipo foi baseada no material citado por McCormick (1914), que menciona a coleta na área vizinha a Xalapa no México por W.J.G. Land e Chales R. Barnes no outono de 1906 e 1908.

Symphyogyna brasiliensis iNees \& Mont., Ann. Sci. Nat. Bot., ser. 2,5: 67. 1836.

Basiônimo: Jungermannia brasiliensis Nees, FI. Bras. 1: 328. 1833.

Localidade-tipo: Brasil.

Gametófitos dióicos, prostrados, verde-claros, 10-60 × 2-5mm. Ramificações bifurcadas ou não, talo ondulado, margens lisas até lobadaš, papilas mucilageníferas abundantes no ápice do talo. Em corte transversal, asa uniestratificada, nervura com feixe prosenquimático, rizóides abundantes por todo o talo. Anterídios e arquegônios recobertos por uma escama, dispondo-se ao longo da nervura mediana na superfície dorsal, arquegônios agrupados.

Distribuição geográfica: Goiás, Minas Gerais, Rio de Janeiro, São Paulo e Rio Grande do Sul (Yano, 1984b).

Material examinado: Rio de Janeiro: município de Rio de Janeiro, Parque nacional da Tijuca, col. D.P. costa 21, 10-IX-1983 (RB230145).

Comentários - S. brasiliensis cresce sobre solo úmido, desde lugares sombreados até expostos diretamente ao sol.

A localidade-tipo de $S$. brasiliensis, segundo Bonner (1976), é Minas Gerais, Vila Rica (= Ouro Preto) no Brasil. Mas, segundo Hell (1969), que estudou o material de Jungermannia brasiliensis citado por Martius em 1833, verificou-se que ele é constituído por dois fragmentos estéreis da planta, além de alguns pedaços de Riccardia sp. Mais tarde, Grolle (1980) estabeleceu o lectotipo como Brasil, Estado de Minas Gerais, São João Batista, baseado no material coletado por Martius.

Symphyogyna podophylla (Thunb.) Mont. \& Nees, Syn. Hep. 481. 1844.

Basiônimo: Jungermannia podophylla Thunb., Prodr. Plant. Capens. 2: 173. 1800. Localidade-tipo: África do Sul.

Figuras 16-19. Metzgeria furcata - 16. Aspecto do gametófito (ramificação irregular); 17. Corte transversal do gametófito, nervura central e rizoides; 18. Detalhe do rizóide ramificado, margem; 19. Gametófito com rizóides (vista ventral). 
Gametófitos dióicos, porção rizomatosa prostrada, aderida ao substrato e outra ereta, verde-clara, 20-50 x 2-4mm. Ramificações bifurcadas; planos com margem ligeiramente denteada, papilas mucilageniferas abundantes no ápice do talo. Em corte transversal, asa uniestratificada, nervura mediana com 19 camadas de células, com feixes prosenquimáticos; rizóides abundantes por toda a porção rizomatosa. Anterídios e arquegônios recobertos por escamas e dispostos sobre a nervura mediana na superfície dorsal do talo.

Distribuição geográfica: Amazonas, Minas Gerais, Rio de Janeiro e São Paulo (Yano, 1984b).

Material examinado: Rio de Janeiro: município de Rio de Janeiro, Parque Nacional da Tijuca, Col. D.P. Costa 56, 4-IV-1984 (RB230193).

Comentários - $S$. podophylla cresce no solo ou madeira em decomposição, formando densos tapetes, ou em barrancos úmidos, sombreados, mas bem iluminados.

Hell (1969) e Grolle (1979) apresentam sinônimos para S. podophylla.

\section{Considerações Finais}

As hepáticas talosas crescem na maioria das vezes nos barrancos úmidos, sobre pedras, troncos de árvores ou madeira em decomposição ou sobre folhas de áreas iluminadas, úmidas, porém em locais sombreados da mata.

$\mathrm{Na}$ área do Parque Nacional da Tijuca, apesar de ser região reflorestada, foram encontradas 11 espécies de hepáticas talosas, sendo um número relativamente alto quando comparado com áreas de vegetação natural. Por exemplo, o trabalho de Hell (1969) relata 28 espécies de hepáticas talosas de São Paulo e arredores, sendo coletadas em matas naturais e também em áreas de matas secundárias.

No parque estudado, foi encontrada Dumortiera hirsuta, que geralmente ocorre nas áreas de vegetação natural. Além disso, Metzgeria aurantiaca e Riccardia cataractarum estão sendo mencionadas pela primeira vez para o Estado do Rio de Janeiro.

\section{Agradecimentos}

A primeira autora agradece ao Conselho Nacional de Desenvolvimento Científico e Tecnológico (CNPq) pela bolsa de aperfeiçoamento (Proc. 100579/83) e ao Jardim Botânico do Rio de Janeiro pelo uso irrestrito de suas dependências, equipamentos e materiais.

\section{Referências Bibliográficas}

BONNER, C.E.B. 1976. Jungennannia. Index Hepaticarum 8: 1-44.

CENTRO DE CONSERVAÇĀO DA NATUREZA. 1966. Floresta da Tijuca.

GRIFFIN III, D. 1979. Guia preliminar para as briofitas freqüentes em Manaus e adjacências. Acta Amazonica 9(3): 1-67.

GROLLE, R. 1969.Miscellanea hepaticologica (91-100). Trans. Br. Bryol. Soc. 5(4): 766-774.

GROLLE, R. 1979. Miscellanea hepaticologica 171-180. J. Bryol. 10: 263-272.

GROLLE, R. 1980. Miscellanea hepaticologica 201-210. J. Bryol. 11:325-334.

HÄSSEL DE MENÉNDEZ, G.G. 1962. Estudios de las Anthocerotales y Marchantiales de la Argentina. Opera Lilloana 7: 1-297.

HELL, K.G. 1969. Briófitas talosas dos arredores da cidade de São Paulo (Brasil). Bolm Fac. Filos. Ciênc. Letr., Univ. S.Paulo. sér. Bot. 25: 1-187.

MCCOR MICK, F.A. 1914. A study of Symphyogyna aspera. Contributions from the Hull Botanical Laboratory 196. Bot. Gaz. 58: 401-418.

PÁDUA, M.T.J. \& COIMBRA FILHO, A.F. 1979. Os Parques Nacionais do Brasil. Sér. Docum. Rio de Janeiro.

SCHUSTER, R.M. 1984. Evolution, phylogeny and classifiction of the Hepaticae. In New Manual of Bryology. vol. 2: 892-1070.

YANO, O. 1984a. Briófitas. In Fidalgo, O.\& Bononi, V.L.R. Técnicas de coleta, herborização e preservação de material botânico. São Paulo, Instituto de Botânica. 62p. (Manual no 4).

YANO, O. 1984b. Checklist of Brazilian liverworts and hornworts. J. Hattori Bot. Lab. 56:481-548. 